\title{
Radyoda Dijitalleşme: Sektör İçin Yarını Anlamak
}

\author{
Sedat Özel (Doç. Dr.)
}

iD Kocaeli Üniversitesi Illetişim Fakültesi sedatozel@kocaeli.edu.tr

Başvuru Tarihi: 23.04.2020

Yayına Kabul Tarihi: 04.07.2020

Yayınlanma Tarihi: 24.07.2020

https://doi.org/10.17680/erciyesiletisim.725849

\section{Öz}

Dijital teknolojilerin kültürel üretim ve tüketim biçimlerini değiştirdiği günümüzde bir kültürel endüstri olarak radyo da bu değişimi güçlü bir șekilde yaşamaktadır. Bilgi ve iletişim teknolojilerindeki yakınsama ile başlayan değişimin öncelikle radyo içerik üretiminde akabinde yayınların iletim metotlarında ama en çok tüketim sürecinde gerçekleştiği görülmektedir. Bulut müzik servisleri başta olmak üzere dinler kitleye sunulan farklı hizmet ve içerikler diğer geleneksel iletişim araçlarında olduğu gibi radyoda da dinleyici kaybına neden olmuştur. Ancak bu kaybın şimdilik düşünüldügü kadar yoğun olmadığına vurgu yapan araștırmalar, yine de Y Kuşağı olarak adlandırılan ve yeni iletişim ortam ve araçlarını daha fazla kullanmaya hevesli kitlenin etkisi ile radyonun tehlikede olduğuna işaret etmektedir. Radyonun gelecekte var olabilmesi, onun tanımlanmasında ayırıcı olan temel özelliklerini koruyarak teknolojiyi daha güçlü kullanmasına ve yeni medyanın kullanıcılarına sağladığı, etkileșim, özelleştirme, asenkron iletişim gibi özellikleri içermesine bağlıdır.

Anahtar Kelimeler: Radyo, Dijitalleşme, Yakınsama, İnternet Radyosu. 


\title{
Digitalization in Radio: Understanding Tomorrow for the Sector
}

\author{
Sedat Özel (Assoc. Prof. Dr.)
}

Kocaeli University Faculty of Communication

sedatozel@kocaeli.edu.tr

Date Received: 23.04.2020

Date Accepted: 04.07.2020

Date Published: 24.07.2020

https://doi.org/10.17680/erciyesiletisim.725849

\begin{abstract}
While digital technologies change the style of cultural production and consumption today, the radio as a cultural industry, experience this change powerfully. Starting with the change of convergence in knowledge and communication technologies, the alteration becomes visible initially with the production in radio content right after the transmission methods but mostly in the process of production. Different service and contents offering to the audience as in the other traditional communication tools led to loss of audience particularly the cloud services. Researches underline that the loss is not that intense, however, it indicates a danger to the radio with the effect of generation $\mathrm{Y}$ who are more willing to use the new communication media and tools. The future existence of the radio is depended on the stronger use of technology by protecting its distinctives, fundamental properties and involvement of the features such as interaction, privatization, asynchronous communication which are available in the new media.
\end{abstract}

Keywords: Radio, Digitalization, Convergence, Internet Radio. 


\section{Giriş}

18. ve 19. Yüzyılda buluşların üretime olan etkisi, yer küreye yayılan ticaret, egemenlik ve iktidar mücadeleleri sonucu haberleşmede artan ve değişen ihtiyaçlar telsiz haberleşme teknolojisinin gelişimini müjdelediğinde, ilk elektronik kitle iletişim aracı olan radyonun bu teknolojinin üzerinde yükseleceği kimse tarafından tahmin edilmiyordu. Sonuçta radyo noktadan noktaya bir iletişim sistemi olarak ortaya çıkmıştır ve amaç hızlı, kesintisiz ve kablosuz olarak haberleşmektir. Ancak birinin bir diğeri ile konuşması olarak başlasa da bir süre sonra birinin kitleler ile konuşmasına dönüșen (Berry, 2006) ve dünya savaşları ile kitlesel önemi anlaşılan radyonun bir dönem için toplumsal yaşama etkisi tartışılmaz bir gerçektir.

Diğer yandan günümüzde radyo, geleceği üzerine farklı görüşlerin çatıştığı bir mecradır. Hem sektör oyuncuları hem de iletişim araştırmacıları açısından radyonun geleceği, tahminler olsa da pek öngörülebilir değildir. Nitekim Ala-Fossi ve arkadaşları (2008) tarafından sektör temsilcileri, yayın düzenleyiciler ve araştırmacılarla yapılan radyonun sektörel ve içerik anlamında 2015 yılında ne olacağına dair mülakattan elde edilen bulgular, 2015 yılındaki gerçekler ile örtüșmemiștir. Gelişmiş dünyanın post modern yaşamında, radyonun toplumsal yaşamın dinamiklerini belirlemek üzerindeki güçlü etkisinin geçmişte kaldığı bir gerçektir. Radyonun güçlü bir şekilde etkisini hissettirdiği yıllardaki gibi insanlar dinlemek için radyo alıcısı etrafında toplanmamaktadır. Radyo içeriği ise, yayıncılığın ilk zamanlarına göre çok daha farklıdır. Gündelik yaşam rutininde kent insanı, özellikle de yeni iletişim ortam ve araçları ile meşguldür (Özel, 2015). Bununla birlikte radyonun internet ile daha farklı özellikler edindiği ve aslında mecra olarak güçlü bir değişim geçirdiğini savunanlar için ise radyo, daha önceki terimsel tanımından daha farklı bir şeyi ifade etmektedir. Artık radyo sadece belirli bir alıcı cihazın ötesinde çoğu teknolojik yenilikçiliğin ürünleri olan araç ve ortamlar tarafından sağlanan eğlencenin genel bir terimi olarak görülmektedir. (Pitts, 2006).

Yeni iletişim çağında, salt radyo yayıncılığı bile söz konusu olduğunda geleneksel mecranın ya da aracın sınırlarının ötesine geçildiği, yayınlara ulaşmak adına mecra ve araç çeşitliliği ile buna bağlı olarak sunulan farklı hizmetlerin birbirini tamamladığı bir yayıncılık florasının söz konusu olduğu düşünülebilir. Bununla birlikte internetin radyo ile radyonun da internet ile kurduğu ilişki karmaşık bir etkileşimi içermektedir. Bu etkileşim bir yanda WEB tabanlı hizmetlerin radyonun sonunu getireceğine dönük endişelere haklı gerekçeler sunarken diğer yanda radyonun yeni bir değişimin içinde olduğuna ve daha güçlü bir şekilde varlığına devam edeceğine dair görüşleri de güçlendirmektedir.

2005 yılına gelindiğinde World Wide Web, ticari medya kullanımı için bir platform olarak yeni bir geliştirme aşamasına ulaşmıştı. Web 2.0 olarak anılan bu yapı ile birlikte Last FM, Pandora, Spotify gibi web tabanlı dijital müzik yayın hizmetlerinin ya da kullanıcılarının oluşturdukları içerikleri yayınlayan Podcasting, YouTube, SoundCloud gibi platformların radyonun geleceğine dair oluşturduğu tehdit yeterince açık olmasa da güçlüydü. Buna karşın yayıncıların Facebook, Twitter gibi sosyal ağlar üzerinden yeni şeyler denemesi, yine sadece müziğe dayalı uygulamalara cevap niteliğinde hizmetler geliştirmek konusunda istekliliği, etkileşimli mobil radyo uygulamaları ile çevrim içi akış servislerini dinleyiciye sunmak gibi çabaları, web yayıncılığının bir platform olarak FM yayınlarının yerini almasının ötesinde onu desteklediği ve geliştirdiğine işaret ediyordu (Jauert, Ala Fossi, Föllmer, Lax, ve Murphy, 2017). Örneğin Berry (2014), radyonun içerik üretim sürecinde yararlandığı sosyal mecraların aslında radyoya rakip olmaktan daha çok tamamlayıcı ve radyo deneyimlerini genişleten bir araç olduğuna işaret eder. 
Radyonun mobilite nitelikleri, yakınlığı ve birebir iletişim kurma kabiliyeti nedeniyle yeni teknolojilerin sunduğu kitle iletişim hizmetlerine uyumlu olacağ (Sinton, 2018, s. 64). Bu noktada, internetin etkinliğini artırdığı günümüzde radyonun Web 2.0'ın sunduğu olanaklardan en iyi șekilde yararlanabilmek adına kendini yeniden icat ettiği ileri sürülebilir (Lindgren ve Gail, 2014).

İnternetin etkinliğini artırmasına paralel şekilde ilerleyen bu tartışmalar ana ekseni oluştururken DAB (Digital Audio Broadcasting) olarak adlandırılan ve konvansiyonel hava yayıncılığından kaynaklı sorunlara -enterferans, ses kalitesi, kısıtlı frekans kullanımı vsbir çözüm olarak düşünülen sayısal karasal radyo yayıncılığı, sektörün geleceğine dair bir başka sorunlu alanı temsil etmektedir. Birçok Avrupa ülkesi başta olmak üzere dünyanın farklı lokasyonlarında FM yayıncılığında yaşanan çıkmazlara karşı hevesle başlanan sayısal radyo yayıncılığının geçen onlarca yılsonunda istenilen noktaya ulaşmaması (Lax, 2017) bir yandan FM üzerinden sürdürülen yayınların geleceğini sağlamlaştırırken bir yandan bu yayınların internet ile mücadelesinde de soru işaretlerinin oluşmasına neden olmaktadır.

Sonuçta teknolojik değişimler ve ilerlemeler toplumsal yaşamın her bir noktasında üretim ve tüketim biçimlerini bir şekilde etkilerken radyo, kendi geleceği üzerine yeni bir arayış içine girmiştir. Doğru sorular ve doğru cevapların çok kesin olmadığı radyo yayıncılığının gelecekte ne olacağına ya da nasıl bir şeye dönüşeceğine dair tartışmalar iyimser tahminlerden öteye geçememekle birlikte, günümüzde radyo istasyonlarının yeni iletişim ortam ve araçları ile kurduğu ilişkide başarılı olması durumunda ayakta kalabileceğine dair inanç da güçlenmiştir. Doğal olarak yayıncılar dijital medya rekabetiyle yüzleşmek için yeni bakış açıları aramaktadır.

Radyoda yaşanan dijital değişimin neden ve sonuçlarını anlamak, yayıncılığın geleceğini kavrayabilmek adına önemlidir. Bu çalışmaya göre tüm medyayı etkileyen dijital dönüşümün radyoya etkileri iki ana tema üzerinden gerçekleşir. Bunlardan birincisi üretim biçimleri ile başlayan ve iletim biçimlerine sıçrayarak gelişen süreçtir. Diğeri ise tüketim biçimlerinin hızlı bir şekilde değiştiği ve çeşitlendiği çok seçenekli medya ortamında radyo algısındaki hızlı değişimdir. Çalışma değişimin kuramsal temellerine odaklanmakta ve öne sürülen bu iki noktaya dair alan yazında yapılan tartışmaların yoğunlaştı̆̆ı kavramları ortaya koymayı amaçlamaktadır.

\section{Dijital Teknolojiler Ve Yayıncılıkta Değişen Koşullar}

Radyo her zaman gündelik yaşantımızın bir parçası olmuştur. Aynı zamanda yayıncılığın kârlı bir iş kolu olarak görülür. Günümüzde radyonun yeni dijital araçlar ve ortamların getirdiği zorluklar karşısında ama aynı zamanda bu araçlar sayesinde kendisini tekrar ettiği bir öz medya ortamından bahsedilir.

Dijitalleşme ve internet, başta radyo olmak üzere temelde medya pazarını değiștirmektedir. Bu görüşü ileri sürenlere göre eğlence için harcanan boş zamanda büyük artış olmuştur ve eğlencenin de yeni türleri ortaya çıkmıştır. Artık sadece radyo, TV, dergi veya gazete ile sınırlı olmayan bu yeni dünyada video oyunlar da dâhil geçmişte kendilerine ait ortamları olan tüm içerik, Web tabanlı olarak tüketiciye sunulmaktadır (Cordeiro, 2012). Radyoda dijitalleşmenin iki ana yönü olduğunu ileri süren Hendy (2000), bunları üretimin dijitalleşmesi ve dağıtımın dijitalleşmesi olarak tanımlar. Dağıtımın dijitalleşmesi hem geleneksel hava yayıncılığında hem de İnternet üzerinden sesin aktarılmasına işaret eden yenilikleri içermektedir. 
Radyoda sayısal teknolojiler ilk olarak üretim süreçlerinde etkisini göstermiştir. Doğal ortamda buluna bir ses dalgasının özgün bir elektriksel kopyası olan analog sinyaller (Carlin, 2006), uzun bir süre üretim ve tüketim süreçlerinde var olmuştur. Üretimin dijitalleşme süreci 1990'ların başında ABD ve Avrupa radyo endüstrisinde başlamıştı. Dijital teknolojiye kadarki üretim sürecinde, fiziksel olarak kesilmesi, daha fazlasına zahmetli bir şekilde kopyalanması ve stüdyolardaki hazır materyallerle yayın için karıştırılması gereken manyetik bantlar radyonun içeriklerinin esasını oluşturmuş, bu içerikler analog cihazlarda kaydedilmiş, düzenlenmiş, karıştırılmış, saklanmış ve oynatılmıştır. Dijital teknoloji bu işlemi, ekranda izlenen bir dizi komutla manipüle edilecek bilgisayar dosyaları ile değiştirmiștir. Belirgin bir şekilde, ses dosyaları çok kısa sürede çok sayıda farklı sürüme kopyalanabilir ve değiştirilebilir. Bununla birlikte ses, resim, metin gibi ürünler "bitler"den oluşan kodlanmış dosyalardır ve tüm sistemler temelde dijital ikili kod esasına göre çalıştığı için dijitalleşme, medya üretim platformlarının teknik yakınsamasında oldukça büyük bir potansiyel üretmiştir (Hendy, 2000, s. 215). Öte yandan sayısal kodlama esasına dayalı dijitalleşme bilgi iletişim teknolojilerinin de gelişmesi için gerekli zemini oluşturmaktadır (Holmes, 2009) . Yakınsama "bir"den "çok"a geleneksel iletişim modelini destekleyerek doğrusal medya iletişiminde bir değişikliğe izin vermektedir; artık "bir"e "bir", “çok"tan "bir"e ve "çok"tan "çok"a iletişime olanak sağlamaktadır. Dijitalleşme, telekomünikasyon, bilgisayar ve yayıncılığın bir araya gelmesini sağlamıștır ve hali hazırda radyo yayınlarının aktarımının IP tabanlı hizmetlerle yapılmasını mümkün kılmıştır. Bunun ötesinde, kavram bilgi yönetimi, üretimi ve dağıtımı ile ilgili yeni bir stratejiyi ifade eder. Dijitalleștirme, basın, televizyon, radyo ve çevrimiçi teknolojiler arasındaki sınırları ortadan kaldırmakta, daha önce ayrı ayrı araçlar tarafından sunulan bu özellikler, içerik ve hizmetler tek bir yapı yoluyla ağa bağlı bir bilgisayar veya cihaz tarafından sağlanmaktadır (Cordeiro, 2012, s. 498)

Dijitalleşme, deregülasyonun finali olarak görülür. Buna istinaden dijitalleşme savunucularına göre, niş radyo tanımını ile uyuşan bir uygulamayı gerçeğe dönüştüren, anlamlı kamu tercihi ve daha fazla yerel katılım için alan yaratan ve dinleyicinin daha aktif bir tüketici ve vatandaş haline gelmesini sağlayan yolların sayısında büyük bir genişleme olacaktır (Hendy, 2000, s. 220). Ancak şunu unutmamak gerekir ki radyoya hâkim iş modeli izleyici dikkatini reklamlar üzerinden pazarlama bu bağlamda da bilgi ve eğlence içeriğinin pazarlanmasına dayanmaktadır. Bu durumda radyo yayıncılığı, kültür endüstrisinin sembolik üretim sisteminin bir parçasıdır.

İkili kodlama dili aynı zamanda dağıtımın dijitalleşmesinin de temel özelliği olarak karşımıza çıkmaktadır. DABıın ikili kodlama yoluyla çalışması, yayın spektrumunda sinyal verilerinin etkili bir şekilde sıkıştırılmasının yolunu sağlamakla birlikte, birkaç yayın ya da program servisinin tek bir frekans üzerinden aktarılmasına da olanak sağlamaktadır. Üstün ses kalitesi sağlama kabiliyeti ile ön plana çıkan DAB, hava dalgalarına sığdırılabilecek radyo hizmetlerinin sayısını çarpıcı bir şekilde artırmaktadır. İkili veriler, gökyüzü üzerinden iletilebildiği gibi elbette bilgisayar ağları boyunca da iletilebilir ve bu, İnternet üzerinden radyo için teknik temeli oluşturmaktadır. Hatta bu tür bir web yayıncılığı için giriş maliyeti nispeten düşüktür. Sunucu olarak işlev gören tek bir bilgisayar ve görece ucuz bir yazılıma ihtiyaç duyulur ki zaten hiçbir șekilde geleneksel yayın yapma zahmetine girmeyen ve bu tarz bir yatırım ile sadece internette yayın yapan birçok radyo istasyonu vardır (Hendy, 2000, s. 215). Radyo yayıncılığının sayısal teknolojiler ile aktarılması bağlamında Nyre ve Ala-Fossi (2008, 
s. 42), gerek hava dalgaları üzerinden gerek geniş bant internet ağları ile gerekse de mobil telekomünikasyon ağı üzerinden 9 farklı medya platformunun söz konusu olduğuna dikkat çeker. Bu platformlar hem birbirine rakip hem de birbirini tamamlayıcı işleyiş mantığı ile ses yayıncılığı açısından çeşitli olanakları yayıncı ve dinleyicinin hizmetine sunar.

Telekomünikasyon, elektronik ve bilgisayar teknolojilerindeki yakınlaşma, medya ve yaratıcı içeriklerin geniş ve dar ölçeklerde dağıtılmasına olanak sağlayacak ağların ortaya çıkmasına neden olmuştur. Önce haberleşme teknolojilerinde başlayan beraberinde haberleşme ve kitle iletişim hizmetlerini ayrı ayrı sunan farklı kurumların kendi alanları dışında ötekinin alanına hizmet sağlayabilmesinin önünü açan yakınsama nihayetinde kullanım yakınsaması olarak bugünün medya yapılanmasının temelini oluşturmaktadır. $\mathrm{Bu}$ açıdan bakıldığında farklı medya araçları üzerinden yapılan tüketimin bir araçtan çoklu medya tüketimine doğru kaydığı, ağ, hizmet ve pazar yakınsamasının gerçekleştiği düşünülür (Özel, 2011). Yakınsama, mevcut süreçlere değer katmak ve yenilerini oluşturmak adına medya, bilgisayar ve telekomünikasyonun sinerjileri ve teknolojilerindeki dinamiklerden kaynaklanmaktadır. Bunlar, her cihazın ve içeriğin dijital olarak yeniden kavramlaştırıldığı bir dijital kültür oluşturur. Aynı șey radyo yayıncılığı için de geçerlidir. Yakınsama, bulut bilişim, etkileşim ve katılım radyo yayıncılığındaki en önemli dönüşümü anlamanın anahtar terimleri olarak karşımıza çıkmaktadır (Cordeiro, 2012, s. 496).

Bu gelişmelerin yaşandığı dönemde üretim üzerindeki ekonomik baskıların yoğunlaştığına ve ticari radyolarda kar talebinin de arttığına işaret edilir. Geçtiğimiz 30 yıl boyunca radyoda ve daha genel olarak yayıncılıkta ticarileştirme ve özelleştirmeye doğru eğilim artmıştır. Avrupa'da 1980'lerde neoliberal ekonomi ve ideolojiler, özel şirketler için yayın pazarlarının açılmasına yol açarken kamu hizmeti tekelleri giderek küçülmüştür. 1996 yılında ABD'de yayıncılık alanında yapılan kanuni düzenlemeler ile deregülasyona uyan piyasa yapılanmalarının önü açılmıştır. Daha öncesinde mevcut ekonomileri teşvik eden kültürel politikalar yeni pazarlar açmayı amaçlayan rekabet politikaları ile değiştirilmeye başlanmıştır (Stiernstedt, 2014, s. 292). Deregülasyon ile birlikte halkın ilgisini ancak bireylerin seçme kapasitelerini artırarak ve güvence altına alarak artırmanın mümkün olduğu bununla birlikte hükümetlerin piyasa üzerindeki kontrolü bırakması düşüncesi benimsenmeye başlandı. Bu yaklaşıma göre, mal ve hizmet üreticileri, rakip üreticilerle başarılı bir şekilde rekabet edebilmek için tüketicilerin isteklerine cevap verebilmelidir. Tüketiciler, satın alımlarındaki seçim süreciyle hangi üreticilerin başarılı olacağını belirler. $\mathrm{Bu}$, hem üreticiler arasında tüketicilerin en çok istediği mal ve hizmetlerin üretimine dönük bir rekabete yol açar hem de üreticileri bu mal ve hizmetleri sağlamanın daha az maliyetli yollarını aramaya zorlar. Deregülasyon, bir başka deyişle, en çok istenen radyo servislerinin en uygun maliyetli dağıtımının ortaya çıkmasına izin veren rekabetçi bir pazarın oluşmasını sağlayan yol olarak görülmüştür (Hendy, 2000, s. 216). Öte yandan üretim dinamikleri ve piyasayı oluşturan sektörün refleksleri düşünüldüğünde yine de bir kontrol sürecinin işleyeceği yine o zamanlardan dile getirilmiştir. Hendy'e (2000, s. 230) göre değişim için sosyal güç dengesine bağlı olarak icatların çeşitli teknik prototipleri engellenebilir veya ileriye itilebilir. "Radikal potansiyelin bastırılması yasası" nın "cüretkâr" operasyonu, önceden var olan sosyal ilişkileri radikal bir şekilde bozabilecek teknolojinin boğulduğu anlamına gelir. Dijital radyo da teknolojinin gelişmesinin dinamikleri bağlamında belirli bir şekilde belirli bir yönde gelişmektedir. Dijital radyo alanında, bu denetleyici ihtiyaçlar ezici bir şekilde en büyük radyo operatörlerinin politik 
ekonomik çıkarları gibi görünmektedir. Ticari radyo endüstrisi dijitalleşme sürecinde oyunun kurallarını ve piyasa koşullarını belirleme eğiliminde olacak, küçük operatörlerin büyümesini engellemeye çalışmak ya da risk eşiğini geçebilecek kadar büyük olanların genişlemesi ve pekiştirilmesini kolaylaştıracak refleksler ortaya çıkacaktır.

Yine de geçen yıllarda yeni medya formlarının yükselişi ile birlikte sektör oyuncuları arasında izler/dinler kitle ve reklam verenler için rekabet arttı. Müzik yayınını programlama için kullanılan dijital araçlar ya da radyo spikerlerinin seslerini kolayca yayın planına kopyalamasını sağlayan ses kayıt teknolojileri gibi yeni üretim teknolojileri radyo üretimindeki maliyet verimliliğini rasyonelleştirerek karı artırmayı mümkün kıldı. Ancak dijital teknolojiler de yeni rekabet biçimleri yarattı ve izleyiciye hitap eden yeni modları teşvik etti. Örneğin, yeni medya platformları dinleyiciler ve üreticiler arasındaki ilişkiyi yeniden yapılandırdı. Podcasting, radyo materyali tüketmenin yeni yollarına yol açtı ve yeni grupların kendi radyo programlarını üretmelerine ve dağıtmalarına izin verdi (Bonini, 2014) (Ferguson ve Greer, 2011).

Bununla birlikte İnternet üzerindeki müzik hizmetleri veren platformlar ile radyo yayıncılığı birbiri yerine kullanılmaya başlandı. Hatta endüstri literatüründe bile dijital platformlar ve dijital radyo sıklıkla birbiri yerine kullanılmaktadır. Bir dijital platform kesinlikle, ses ve / veya görsel bilgileri darbe kodu modülasyonu ile işleyen herhangi bir analog olmayan sistemdir. Buna karşılık, dijital radyo, akıllı telefon uygulamaları, çevrimiçi radyo istasyonları, HD radyo, ses podcastleri ve uydu radyo gibi dijital bir platform aracılığılla gönderilen ve alınan bir ses ürününü ifade eder (Punnett, 2016, s. 5). Öte yandan sadece bir ses sinyalinin internet üzerinden ulaştırılmasının radyo terimine uygun olup olmadığı da sorgulanmıştır. Mesela etkileşimli hizmetler ile örtüșen webdeki radyo hizmetlerinin, radyonun bilinen tanımı içinde olamayacağına vurgu yapılır. $\mathrm{Bu}$ noktada Tacchi, web üzerindeki yayınların alışageldik yapıdan farklı olmasına istinaden radyo kabiliyeti (radiobility) ifadesini ön plana çıkarır (Baker, 2009, s. 8)Bu aynı zamanda yayıncılık sektöründe köklü değișimleri de ifade eder (O’ Neill, 2009, s. 262-264).

Ancak dijital değişim iletim tekniklerinde ayrı, tüketim biçimlerinde ayrı sorunları da beraberinde getirmiştir. Örneğin dijital iletim teknolojisi DAB ya da DRM, teknik olarak kendisini kanıtlamış olsa da ticari olarak belirli kaygılar ile anılmıştır (Özel, 2014, s. 175-177). 1990'lı yıllarda başlayan ve geleneksel radyo yayıncılığında dijital bir atılım olarak görülen DAB geçen yıllar içinde Avrupa kıtasında farklı uygulamalar, denemeler ve kararsızlıklar ile bir çıkmaza girmiş durumdadır. Karasal yayınlarda ses kalitesinin ve verilen hizmetlerin çeşitlendirilmesinin önünü açacağı düşünülen DAB'ın yayılımı geçen yıllar içinde beklenen seviyeye ulaşmazken FM yayıncılı̆̆ı da internetin yayılımına ră̆men popülerliğini korumuştur. İlk on yıl boyunca, DAB, gelişmiş multimedya kapasitesine sahip alternatif, daha verimli teknolojilerle rekabetin artmasıyla karşı karşıyaydı, bu nedenle 2006〉da DAB + olarak adlandırılan zorunlu bir güncelleme yapıldı. Bu gelişmenin zirvesinde, Dünya DAB Forumu bile Dijital Multimedya Yayını'ndan sonra adını Dünya DMB olarak değiştirdi ve Fransa, 2007'de “Dijital Radyo Mondial”in (DRM) yanı sıra, dijital radyo için standart olarak DMB'yi seçti. Finlandiya, DAB'dan ayrıldıktan sonra, Nokia tarafından geliștirilen ve yakın zaman kadar Avrupa Komisyonu tarafından resmi olarak desteklenen, 2008'de AB'nin resmi standartlarından biri haline gelen bir mobil TV sistemi olan DVBH’ye (Dijital Video Yayını Elde Taşınabilir Cihazlar) güvenmeye başladı. Görsel radyo için (örneğin, Visual Radio ${ }^{\mathrm{TM}}$ ) ve karasal radyo yayınlarını IP veri iletimi ile birleştiren hibrit radyo alıcıları (örneğin, Radio DNS) tanıtıldı. Bununla birlikte, multimedya radyo, Avrupa tüketici pazarlarında pek başarılı olamadı. Son DVB-H servisleri 2012 yılına 
kadar yayında kaldı. DMB hizmetleri de kademeli olarak kapatıldığı için, Dünya DAB Forumu, 2015 yılında orijinal ismini geri aldı. DRM, Hindistan'daki geniş kapsamlı yayına rağmen Avrupa'da çok fazla yer alamadı (Jauert, Ala Fossi, vd. 2017). Sonuçta FM yayıncılığın kısıtlarını aşmak adına geliştirilmeye başlanan, bir anlamda da gelişen web pazarlarının getirdiği yeniliklere geleneksel sektör oyuncuları için bir cevap olabilecek DAB teknolojisi ticari kaygılar ve teknoloji üzerine hakimiyet savaşları nedeniyle istenilen ve hedeflenen başarıyı yakalayamamıștır.

Aslında sayısal iletişim teknolojileri ile radyo iki ana tartışmanın ön plana çıktığı bir kavşak noktasındadır. İlki yayınların ulaştırılmasında kullanılacak yaygın teknoloji ile ilgilidir. DAB, DRM, internet gibi farklı yöntemlerden hangisinin ağırlıklı kullanılacağı tereddütlü tartışmaları içinde barındırmaktadır. İkinci ana konu ise kültürel, politik ve ekonomik süreçler ile ilişkilidir. Örneğin bireysel dinleme seçeneklerinin giderek arttığı bir ortamda radyo yayıncılığının içinde barındırdı̆̆ı kolektiflik sorgulanır. Sonuçta her bir yayın tekniği kendi kapsama alanını içermektedir. Bununla birlikte ve belki de daha önemlisi internetin radyo yayıncılığını her anlamda yeniden tanımlamasıdır (Priestman, 2013, s. xi). Bununla birlikte, son yıllardaki teknolojik değişiklikler, radyo yayıncılı̆̆ında (Williams tarafından 70'li yıllarda televizyon ve radyo yayıncılığında yayın planlamasının kuramsal olarak tanımlanması için ortaya konmuş bir ifade olarak) akış yönetimi teorileri ve uygulamalarına meydan okudu. Merkezi yayın modeline dayanan zaman ve yer ilişkili yapısıyla dinleyici için nispeten sabit desenlerden oluşan geleneksel radyo, yine görece istikrarlı dinler kitlelere sahiptir. Bunun yanında dinleyici geri dönüşleri ve etkileşimi sınırlıdır (Baker, 2011, s. 122). Yeni dağıtım modlarının (podcasting, isteğe bağlı servisler, çevrimiçi akış) ve yeni içerik biçimlerinin (video, metin, görüntüler) artan önemi nedeniyle, "zamanın değeri” üzerine odaklanma önemini kaybetmeye başlamıştır. Dikkatler çok platformlu üretime yöneldiğinden akış ve akış yönetim teorileri ve uygulamaları da yeni bir yönelim içindedir. Müzik ve içerik akışından izleyici akışlarına doğru bir odaklanma söz konusudur. Üreticiler sadece dinleyicilerin zamanlarını nasıl kullandıklarını (dinlemeye devam ettiklerini) değil, aynı zamanda farklı platformlar ve içerik biçimleri arasında hareket biçimlerini de etkilemeye büyük ilgi göstermek zorundadır (Stiernstedt, 2014, s. 295).

Radyodaki yakınsama ve bulut iletişimi gibi örnekler medya içindeki iletişimsel süreçlerin değiștiğine dair güçlü örnekler olarak ileri sürülürken (Cordeiro, 2012), anlamı ve sınırları tartışmalı bir şekilde değișen sektörde yeni oyuncular, geleneksel medya şirketleri ile birlikte, tüketicileri içerik üreticisi ve dağıtıcısı olarak görmektedir. Bununla birlikte yeni medya ortamı kendi yayıncılık anlayışını gelenekselleştirmeye çalışırken mevcut geleneksel radyo yayıncılarına da meydan okumaktadır. Teknolojik kaymalar ve medya yakınsaması nedeniyle, bir ortam ve bir endüstri olarak radyonun değişimi bu iş kolunda faaliyet gösteren kuruluşların iş modelleri ve çalışma şekillerini yeniden yapılandırmaya zorlamaktadır (Stiernstedt, 2014). Radyoda yakınsama yayıncıların daha önce farklı olan araçları dijital cihazlardaki ortak ara yüzlerde birleştirmeyi kabul ettikleri ağ mimarisini ifade eder (Cordeiro, 2012, s. 498).

Radyoda yaşanan dönüşüm ekseriyetle yayın iletim şekillerinde bir değişimi açıkça ifade ederken geleneksel iletim modellerinin imkân vermediği çeşitli alternatifleri de beraberinde getirmektedir. Ancak mümkün olan en geniş kitleye ulaşmak hedefindeki radyo istasyonları için bu alternatifler aynı zamanda farklı dezavantajları da içinde barındırır. Diğer taraftan bir radyo istasyonu için her bir teknik birbirini tamamlayıcı ve birbirine rakip pazarlara hizmet sunmayı ifade etmektedir. Her bir iletim tekniğinin kendi hizmet potansiyeli de 
düşünüldüğünde geleneksel radyo yayıncılık siyasasında da bu yapılara uyumlu bir değişimin gerekliliği ortaya çıkmaktadır (Özel, 2014, s. 185).

\section{Yeni Rekabet Ortamları İçinde Radyo}

Yayıncılık alanında teknolojik değişimin etkilerini güçlü bir şekilde hissettirdiği 2000'lerin başında radyo için karamsarlığın egemen olduğu bir yaklaşım mevcuttu. CD, MP3 gibi teknolojilerin bireysel tüketimi güçlendirici etkisi, radyo sektörünü oluşturan kuruluşların bu tür gelişmelere doğru cevaplar verememesi durumunda çlkmaza gireceğine dair güçlü kanıtlar sunuyordu. Akabinde radyonun müzik tüketimi üzerine etkisine meydan okuyan müzik servislerine artan ilgi, sektör üzerinde yeni teknolojilerin yıkıcı etkileri konusunda daha fazla endişenin ortaya çıkmasına neden oldu.

Aslında radyonun 1920'deki ilk ticari yayınından bu yana radyo sayısız değişiklik ve zorlukla karşı karşıya kalmıştır. Format değişikliklerinden yaratıcı reklam mesajlarının etkisine radyo, bir yayın aracı olarak büyümesinin bir parçası olan değişimi başarılı bir şekilde gerçekleștirmiştir. Bununla birlikte bir ortamın büyümesi ve gelişimine özgü değişimin ötesinde radyo, fonograf, kaset, CD gibi birçok piyasa tehdidine karşı da başarılı bir sınav vermiştir. Ancak, belki de bugün radyoya yönelik en önemli tehditlerden biri İnternetin getirdiği henüz çözülmemiş olan tehdittir. İnternet ve mobil ağların bir sonucu olarak, radyonun en büyük varlığı- taşınabilirliği- aynı zamanda en büyük yükümlülüğü haline gelmiştir. İnternet ve mobil ağlar, tüketicilerin medya alımlama ve etkileşim biçimleri ile aynı zamanda beklentilerini değiştirdi. Radyo geleneksel ve güvenilir bir teknolojidir ancak yayınların ulaşma biçimi ve etkileşimdeki eksilik bildiğimiz üzere geleceğini tehdit etmektedir (Pluskota, 2015, s. 325-326).

Örneğin, internetteki müzik akış servislerinin sundukları hizmetlerde radyoya göndermede bulunması (Last FM ya da Spotify'da şarkı radyosu gibi), bu kuruluşların geleneksel medyayla sembolik bağlarını terk etmediklerinin sağlam bir kanıtı olarak görülür. Diğer yandan yeni medyanın kullanıcıları tarafından daha hevesli bir şekilde kucaklandığı düşünülmektedir. Özellikle de müzik akış servislerinin sundukları çalma listeleri oluşturabilme, dinleme alışkanlıklarını sosyal medya üzerinden insanlarla paylaşma imkânı gibi radyonun pasif bir ortam olduğuna dair alt göndermeleri, bu hizmetlerden yararlanan kullanıcılar tarafından da karşılık görmektedir. Çalma listelerini ve dinleme alışkanlıklarını paylaşma yeteneği, yaşamlarının diğer yönlerini yeni medya aracılığıyla paylașmaya alıșkın olan kullanıcılara hitap etmektedir (Glantz, 2016). $\mathrm{Bu}$ noktada radyonun 1950'li yıllarda televizyonun baskısı sonucu müzik sektörü ile kurduğu güçlü ilişkinin ve Top40 radyoculuğu gibi iş modellerinin sorgulandığı bir durum ortaya çıkmıştır.

Müziğin, yeni medya teknolojilerini benimsemesiyle ilgili bir başka tema da mobiliteye odaklanmasıdır. Müzik yayın hizmetleri için bilgisayarlar, akıllı telefonlar, araç müzik sistemleri ve ev eğlence sistemleri gibi müzik yayını hizmetleri için çok daha fazla cihaz seçeneği söz konusudur ve bu bir bakıma platform agnostisizmine bir cevap niteliği taşımaktadır. Aslında geleneksel radyo yayıncılığı da her zaman mobil olmuştur ve bu konuda, her zaman birden fazla yerde ve birden fazla cihazda mevcut olmuştur (Glantz, 2016). Bununla birlikte, 2007'de Apple iPhone'un tanitımı, hem Nokia cep telefonları için hem de Apple'ın kendi iPod'u gibi ayrı taşınabilir ses cihazları için sonun başlangıcı olmuştur. Ekonomik krizlerde bile yeni tür dokunmatik ekranlı akıllı telefonlar ve tabletler tüketici pazarlarında çok popüler hale gelmiştir. Bu cihazların çoğunda yerleşik FM alıcıları yoktur, bu nedenle cep telefonlarındaki ses, dijital yazılım uygulamaları 
kullanılarak mobil genişbant verileri olarak çoğunlukla 3G / 4G üzerinden tüketilir (Jauert, Ala Fossi, Föllmer, Lax, \& Murphy, 2017). Aslında müzik akış servisleri, müziği yeni medya biçimlerine genişletme iddiasında değildir. Aksine, ürünlerinin zaten müşterilerin sahip olduğu cihazlarda ve müzik sistemlerinde mevcut olacağı iddiasındadırlar. Sonuçta müzik servislerinin dili sadece olağanüstü bir bireycilik duygusuna hitap etmekle kalmaz aynı zamanda teşvik eder (Glantz, 2016).

Nokia'nın 2013 yılında yaptırdığı bir araştırma, insanların 16 saatlik uyanık kaldıkları bir günde akıllı telefonlarını ortalama 150 kez kontrol edip dokunduğunu keşfetti. 2013 yılında BBC One Radyodan Ben Cooper, dinle izle paylaş olarak adlandırdığı yeni radyo stratejisini açıkladı. Ona göre radyo içeriği ile bağ kurmak radyo içeriğine maruz bırakmaktan daha değerliydi. Bu strateji radyoyu yolda dinlemeye alışmış insanların radyoya özel uygulamalar ile günde birkaç kez dokunmatik ekranları üzerinden etkileşimde bulunmalarına dayanıyordu. Artık radyo içeriğine yönelik dikkat, yalnızca işitsel ve görsel değildir; dokunma duyusuyla da ilişkilidir. İnsanlar en sevdikleri radyo programlarını istek üzerine ya da canlı dinleme seçeneği sunan Tuneln, Stither, Spreaker, SoundCloud, Mixcloud gibi özel uygulamalar üzerinden dinlemek için ekrana dokunuyor. Dinledikleri şarkıların videoları için Youtube linkine tıklıyor ya da sosyal ağ platformlarının kısa yol tuşlarını kullanarak dinledikleri radyo istasyonu tarafından üretilen içeriği paylaşmak, yorum yapmak, bahsetmek ya da beğenmek adına bu platformların sayfalarına geçiş yapıyor, "Shazam" uygulaması ile radyoda çalan şarkı hakkında bilgi ediniyor (Gazi ve Bonini, 2018, s. 109).

Bu gelişmeler düşünüldüğünde sektör için yeni iş modelleri geliştirmek kaçınılmazdır. Medya dağıtım sistemlerinin ve kaynakların çoğaltılması, yeni yayın stratejileri ve içeriğin yeniden tanımlanması, bir ev içi ve ev dışı, canlı ve zaman ayarlı tüketim için mobil cihazlara uyarlanması anlamına gelir. Bunlar, izleyicilerin tüm platformlarda ve tüm ortamlarda medyayla etkileşime girmesini sağlar; bu, radyo için, ses cihazlarının çevrimiçi, mobil ve yeni gelișen platformlar için ekranlarla birleștirileceği anlamına gelir (Cordeiro, 2012, s. 505). Ama temel olarak, yeni ürün geliştirme maliyetleri yüksektir; yaratıcı süreç tahmin edilemez olabilir, özgün ve ilginç fikirlerin gelişmesi zaman alır ve üretim sürecinin rasyonelleştirilmesi zordur. Bu, yüksek risk ve buna bağlı olarak bu riskle başa çıkma ihtiyacı ile karakterize bir iş ortamı yaratır. Diğer taraftan radyo ve televizyon için üretilen içerik, diğer ürünlerden faklı olarak kamusaldır, daha açık bir ifadeyle uygun bir alıcı cihaza sahip herkese bu ürünler açık ve erişilebilirdir. Yayınlar, müşterilerden doğrudan ödeme almak yerine, genellikle reklam yoluyla finanse edilir. Yayın endüstrileri, bir anlamda reklam verenlerine kendilerini takip eden izler/dinler kitlelerini kiralar. Ancak bu, yayın yapan şirketler için tüketim belirsizliği olarak adlandırılabilecek bir soruna yol açar. Radyo ve televizyonda yapımcı ve tüketici arasındaki kaçınılmaz uçurumun yanı sıra, belirli bir anda izleyicinin kanalı değiștirmesi, odadan çıkması, dikkatini başka bir yere hedeflemesi ya da alıcıyı kapatması olasıdır.

Diğer yandan radyo dinleyicisi artık parçalanmış durumdadır. Farklı hizmetler arasında ihtiyaç ve tercihlerine en uygunu seçerken yaşam tarzıyla da örtüşen içeriği tüketmeye meyillidir. 1980'den sonra doğanlar olarak tanımlanan milenyum nesli ya da Y kuşağl, "kendine güvenen, kendini ifade eden, liberal, iyimser ve yeni fikirlere, yeni yaşam tarzlarına açık" olarak tanımlanmıştır. Günümüz dinleyicisi, radyo ile büyüyen geleneksel radyo dinleyicisinden seçimleri ve kendisine sunulanları ile daha farklıdır. Ancak değişen tüketicinin mutlak radyoya ilgisizliğinden bahsetmek mümkün değildir. Buna karşın Y Kuşağı, teknolojik ilerlemede önemli bir rol oynamaya devam edecek ve eğer 
teknoloji tatmin edici değilse, onu bir kenara itecektir. Bir teknolojiyi tatmin edici kılacak tanımlayıcı özellikler ise seçim, özelleştirme ve erişimdir. Dinleme eğilimi açısından bu, neredeyse sınırsız bir içerik kataloğuna erişim, talep edilen içeriği arzu edilen zaman diliminde dinlemek anlamına gelmektedir. Bu durumda bir CD satın almak da Y kuşağı nesli için o kadar da önemli değildir (Pluskota, 2015, s. 331).

$\mathrm{Bu}$ açıdan bakıldığında radyo endüstrisinin karşılaştığı en büyük zorluk, yenilikçi, etkileşimli ve dinleyicileri hem karasal yayınlarda hem de platformlarda bulunan kaliteli içeriğe iten kapsamlı bir dijital stratejiye duyulan ihtiyaçtır. Radyolar için, dijital platform mücadelesine cevap vermek, izleyicilerin arzu edeceği içeriği oluşturmak için hem inovasyonu hem de yeni yatırımı gerektirecektir. Ancak, radyo endüstrisinin mali durumu, bunun gerçekleşmesi için gerekli ekonomik kaynakları sağlama yeteneği hakkında şüphelere neden olmaktadır çünkü Albaran'a göre radyo endüstrisinin gelirleri uzun süredir düşüş eğilimindedir (Punnett, 2016, s. 15-16). Radyo çok zaman önce primetime medyası vasfını yitirmiştir. Ancak ekonomik veriler anlamında gerilemenin bu sanayinin çöküş göstergesi anlamına gelmediği ileri sürülmektedir. Bilakis, sektör oyuncularının teknolojilerini ve rollerini tekrar gözden geçirmesi için bir işarettir. Örneğin, teknolojik gelişmeler gazete ve dergi endüstrilerinin çalışma şeklini etkilemiştir. Tüketiciler haber ve bilgiye çevrim içi ulaşmaya başladıklarına bu endüstri tamamen ölmek yerine kendilerini ve bilgiyi nasıl tüketiciye ulaştıracaklarını yeniden tanımlamak zorunda kalmışlardır. Ancak tüketici tek endişe değildir. Bütçeleri ile medya maliyetlerini karşılayan reklam verenler, değişen tüketici ortamlarına ulaşmak amacıyla reklam bütçelerini farklı platformlara ve medya ortamlarına çeşitlendirmeye zorlanmıştır (Pluskota, 2015, s. 327)

Öte yandan medya tüketimindeki değişiklikler bizi hem ses dinleyicisini (FM yayıncılığı ve çevrimiçi akışlar) hem de kullanıcıyı (sosyal ağlarda etkileşime girerek ve radyo web sitelerini keşfederek) birleştiren, aynı zamanda web 2.0’ın sosyal bağlamında aktif olarak içerik üreterek ve paylaşan bir tür dinleyiciyi düşünmeye itmiştir. Bu açıdan bakıldığında radyo artık sadece dinleyicilere sahip değildir, aslında çevrim içi var olan ve yeni bir dinleme biçimine sahip; bu açıdan da "e-dinleyiciler" olarak adlandırılacak bir kitleye sahiptir. "E-dinleyici", sadece bir radyo dinleyicisinden daha fazlasıdır. Medya ile (ve özellikle radyoyla) mevcut platformlar üzerinden mümkün olan her şekilde etkileşime giren, içerik üreten, çapraz medya ve çok platformlu bir medya tüketicisidir (Cordeiro, 2012, s. 502). Aslında bir bakıma bu nedenle yeni medya platformları, sosyal medya aracılığıyla yeni metinlerin inşası da dâhil olmak üzere üretim uygulamalarına giderek daha fazla dâhil edilmiștir ve bunu yaparken de geleneksel yayınları tamamlaması ve üzerine ilave etmesi hedeflenmiştir. Örneğin DJ'ler ve sunum yapan kişiler, dinleyicilerle iletişim kurmak için Facebook ve Twitter gibi sosyal ağ ortamlarını kullanır ve sıklıkla kişisel bloglarda mikrofondaki kişilikleri ve gerçek kimlikleri arasındaki boşlukları doldurmak için kendilerini ifşa ederler. Sesli yayınlar için içerik üretmenin yanı sıra, DJ'ler ve sunum yapan kişiler dijital dağıtım için metinler, videolar, resimler ve diğer "sesli olmayan" materyaller üretmektedirler. Bunun sonucunda da çeşitli medya platformlarında giderek daha fazla çalınan radyo, çok yönlü bir ortam haline gelmektedir (Stiernstedt, 2014, s. 291-293).

Alternatif mobil dinleme seçeneklerinin artması başta olmak üzere tüm bu gelişmeler, radyonun tanım olarak neyi ifade ettiğinin de yeniden düşünülmesine ve tartışılmasına neden olmaktadır. Radyo yayıncılığı endüstrisi, "AM", "FM" ve uydu radyo kanalları üzerinden ses programlarını ileten yayın istasyonları, büyük holdingler ve içinde birkaç radyoyu bulunduran şirketlerdir. Diğer taraftan bu tanım yalnızca çevrim içi olarak 
çalışan operatörleri hariç tutmaktadır. Mobil medya endüstrisinde dinleyici için rekabetin artması, radyo yayıncılığının geleneklerinden sapan, ancak tüketicinin dikkatini çeken birçok farklı hizmeti içermektedir (Pluskota, 2015, s. 326). Bugün radyo, multimedya, çoklu platform ve yakınsaktır. "FM dönemi" den farklıdır; ses ve görüntüye sahiptir, (daha fazla) etkileșimli, (daha fazla) katılımcı, paylaşılabilir, asenkron, tekrarlanabilir, yeniden üretilebilir, aranabilir, özelleștirilebilir, süreksiz, hipermetinsel, doğrusal olmayan ve talep üzerinedir Sonuçta etkileşim, yakınsama ve bulut bilişim, radyo yayıncılığına yeni bir yaklaşım getirmiştir. İsme önek ekliyor olsaydık (çevrimiçi radyo, e-radyo, web radyosu, siber radyo, Internet radyosu), dijital dünyanın bir sembolünü de ekleyerek kelimenin adını değiştirebiliriz: @ (Cordeiro, 2012, s. 503).

Baker (2009), Internet üzerinden radyo yayınlarının gelişmesini "geleneksel radyoyu hem güncelleyen hem de küreselleştiren hibrid bir teknoloji” olarak adlandırmıştır. Bonini (2015) ise, Dijital kültürün, sosyal medyanın ve akıllı telefonların yükselişi ve radyo ile melezleşmesini "radyo dinlemenin dördüncü yaşı" olarak görmektedir. Dinleyiciler sadece öncekinden daha gürültülü değildir, aynı zamanda ağa bağlıdır. Hanson (2011) ise, radyonun internet ile birlikte yeni bir altın çağ yaşadığına işaret etmiştir. O’na göre ilk altın çağ 1930'larda radyoda görülmeye başlanan eğlence programlarının etkisi ile başlamıştır. TV'nin toplum üzerindeki hâkimiyeti ile birlikte müzik odaklı programlar 2 . altın çağı işaret etmektedir. Yayınların AM bandından FM bandına taşınması ise 3. altın çağın başlangıcının oluşturmaktadır. Şimdi ise internet ile 4. altın çağa giren radyo, geniş bant ve mobil teknolojisini kullanarak, içerik çeşitliliğini, daha az reklam sürelerini, aynı anda birden çok araç üzerinden ulaşma imkânını ve kişiselleştirmeyi sunmaktadır.

Ancak yine de karasal yayınları dijital dönüşüm ile tehlike altında olan radyo endüstrisinin daha web tabanlı ve multi medya olmaya çabaladığına işaret edilmektedir. Bu çabayı üç farklı ve birbirine destek veren değişken ile aktaran Cordeiro (2012, s. 494), bunları, kapsam (sprektrum dağılımı), diğerleri ile ilişkiyi oluşturmak bağlamında marka ve içerik ve son olarak yayıncıların profesyonel kompleks üretim sistemleri üzerinden kültür endüstrileri çerçevesine uyan iş yapısı olarak tanımlar. İstasyonlar niş dinleyicileri çekmek için kendilerini birbirlerinden farklı şekilde markalaştırmaya çalışırlar, kapsam markalaşma ve içeriği etkiler, marka ise içerik yani radyo formatına bağlıdır. Başka bir deyişle, kapsam bir ülkenin düzenleme sistemi içerisinde spektrum dağılımına göre belirginleşir, bunun ötesinde de yayıncının kapsama alanında (tüm ülke veya belirli bir yer) faaliyet gösteren uygun bir iletim ağı sağlama konusundaki ilgisine göre şekil alır. Radyo istasyonları dinleme konforunu garanti ederek içeriğin dinleyiciye ulaşmasını ve marka ile etkileşimi sürdürmelerini garanti altına almaya çalışır. Böylece dinleme konforu bir anlamda başarılı bir radyo için temel dayanak haline gelir. Bugün karasal radyo yayıncılığı hala önemli bir dağıtım kanalı olmasına karşın rakamlar çevrim içi hizmetin artık FM'in sadece tamamlayıcısı olmadığına işaret etmektedir. Bilakis gençler ve dijital göçmenler için bazı durumlarda çevrimiçi hizmetler FM'in yerini almaktadır (Cordeiro, 2012, s. 494). Karasal radyo yayıncılığının geleceğini şüpheli duruma sokan, medya dinleme deneyimleri Pandora, İtunes ve Spotify gibi özelleştirilebilir hizmetler arasındaki yarıştır. Geleneksel radyo yayıncılığında müzik veri tabanına bağlı bir programlama yazılımı kullanan akış direktörleri akış içinde ne dinleneceğinin seçer. Müzik parçaları, radyo yöneticisi tarafından belirlenen istasyona özgü kurallara (tempo, stil, sanatçı, tekrarlar vb.) dayalı çalma listeleri oluşturan yazılıma girilir. Çağrılar ve istekler dışında, dinleyicinin çalma listeleri veya içerik üzerinde neredeyse hiçbir kontrolü yoktur. Buna karşılık, İnternet tabanlı medya dinleme deneyimlerinde, kullanıcı 
dinleme alışkanlıklarına ve etkileşime dayalı çalma listeleri oluşturmak için karmaşık algoritmalar veya formüller kullanılır (Pluskota, 2015, s. 333).

Bu durumda sektörün ayakta kalabilmesi açısından temel soru ne kadar istasyonun olduğu değil bu istasyonların içerik ve hizmet çeşitliliğidir. Bulut tabanlı müzik servislerinin ana rakip olduğu çok seçenekli bir yayıncılık ortamında DJ'ler başta sosyal ağları kullanarak istasyonun web sitesindeki daha fazla içeriğe doğru dinleyiciyi yönlendirmek gayretiyle hareket etmektedir. Artık radyo için önemli olan sadece dinleyicinin kanalda kalması değil aynı zamanda markanın şemsiyesi altındaki farklı medya platformları arasında hareketini sağlamaktır (Stiernstedt, 2014, s. 295). Sektör uzmanlarından Slade (Punnett, 2016, s. 6), canlı ve yerel olan sesin insanların gündelik rutinlerine eşlik ettiğini belirtmektedir. Radyoların rekabeti, kasetlerden CD’lere, Mp3'lere ve nihayetinde uygulamalara doğru değișirken, en sevdiğimiz radyo kișiliği hala bize en iyi müzik, güncel konular, haberler, trafik durumu ile ilgili bilgiler vererek bizi eğlendirmektedir. Bir başka sektör uzmanı Talbot, ticari radyonun mümkün olan en fazla dağıtım kanalı üzerinden içeriklerini dağıtmaya devam edeceğini ve bu kanalların da nihayetinde tüketiciler tarafından belirleneceğini ileri sürmektedir. Farklı platformlar ortaya çıktıkça radyonun bu platformları benimsemek konusunda çok açık ve duyarlı olması gerekmektedir. Odak noktası, çok saatlik gün bölümleri üretmekle ilgili olmayacak; anlamlı içerik oluşturmak hakkında olacaktır. İster iki dakika ister üç saat programlama olsun, izleyicinin istediği esas olacaktır. Montana'ya göre bu durum nasıl yayınlandığına bakılmaksızın, dinleyicinin çeşitli platformlarda içerik arama eğilimi ile ilişkilidir. Slade ise bu durumu dinleyicinin durgun ve tek boyutlu bir varlık olmaması ile bağdaştırır (Punnett, 2016, s. 10).

Öte yandan Avrupa'da sektör oyuncuları ve düzenleyici kuruluş temsilcileri gelecekte geleneksel radyo yayıncılık değerlerinin devam edeceğine dair güçlü bir inanca sahiptir. Sosyal medya kullanımı, talebe bağlı içerik hizmetleri, görselleşmiş radyo içeriği her ne kadar daha dikkat çekici olsa da lineer akışa dayalı bugünün FM yayıncılık modeli bu hizmetler ile birlikte var olmaya devam edecektir (Jauert, Ala Fossi, vd., 2017, s. 22). Sonuçta bugün hem geleneksel yollarla dinleyiciye ses hizmeti ulaştıran radyolar (ki bu yollara uydu yayınlarını da dâhil etmek gerekir) hem de internet üzerinden ses hizmeti veren oluşumlar mevcuttur. Bu durumda sadece radyo dinleme deneyiminin ötesinde bir medya dinleme deneyiminden bahsetmek gerekir. Medya dinleme deneyiminin yapısı, bugün çeşitli teknolojilerde mevcut olan çok sayıda dinleme seçeneğinin kapsamlı bir temsili olarak önerilmiştir. Bu seçenekler arasında sesli kitaplar, haber yayınları, müzik, çalma listeleri (playlist), Podcast’ler ve daha fazlası gibi içerikler bulunur ve dinleyici tarafından geleneksel yayın, talep üzerine, cihaz üzerinden, veri, İnternet bağlantısı ya da dosya aktarımı yoluyla alınabilir. Medya dinleme deneyimi medya tüketiminin işitsel yönünü temsil etmekle birlikte kimi durumda video izlemeyi de içerebilir. Bu durumda tüketici medya izleme deneyimine katılacaktır. Aslında bu geçişgenlik bugünün medya ortamını anlamak için de önemlidir (Pluskota, 2015, s. 328).

İnternet tabanlı medya dinleme deneyimlerini destekleyen teknoloji, karasal radyo istasyonlarının kucaklaması gereken gelişmeleri temsil etmektedir. Karasal yayın yapan radyo endüstrisi, kullandığı yayın teknolojisi mimarisini, İnternet tabanlı medya dinleme deneyimleri ile rekabet edebilecek şekilde geliştirmeye odaklanmalıdır. Radyo endüstrisi kendini canlandırmaya ve dönüştürmeye çalıştığından, belki de çözüm, radyo endüstrisinin talep üzerine bir zihniyeti benimsemesidir. En büyük zorluk, radyo böyle bir dönüşümü benimsemeye karar verirse, endüstrinin yetenek yapısına bağlı maliyet yapısını ve masraflarını yeniden düşünmesidir (Pluskota, 2015, s. 333). 


\section{Sonuç Yerine}

Bilgi ve iletişim teknolojiler günlük yaşantımızdaki etkinliğini giderek artırmıştır. Yakınsama kültürü ile birlikte bulanıklaşan sınırlar ve çoklu medya oluşumları insanlara daha farklı deneyimler sunmaktadır. Bu deneyimler tüm kültürel üretim ve tüketim biçimlerini güçlü bir şekilde etkilemiştir ve doğal olarak bir kültürel endüstri alanı olan radyonun da bu çok seçenekli ortamda geleceği tartışmaya açılmıştır.

Aslında radyonun düzenli kendisini yenilediği ve kendisini tehdit ettiği düşünülen her bir yeni teknolojiye uygun şekilde güncellediği bilinmektedir. Televizyona karşı verdiği mücadele kişisel müzik çalarların yaygınlaşması ile farklı bir boyutta devam etmiş olsa da her seferinde radyo sektörü deneme yanılma yoluyla doğru cevapları yakalayarak yoluna devam etmiştir. Ancak günümüzde süregelen değişim daha şiddetli ve keskin bir süreç olarak görülmelidir. Çalışma amacı çerçevesinde yapılan alan yazın taramasından elde edilen bulguların ortak noktaların göre değişimi şu alt başlıklar altında özetlemek mümkündür.

1. Üretim süreçleri: Radyoda dijitalleşme ilk olarak üretim biçimleri ile kendisini göstermiştir. Dijital sistemlerin içerik üretiminde sağladığı kolaylıklar harcanan zaman ve maliyetin azalmasına destek verirken içeriğin çeşitlendirilmesi ve zenginleștirilmesi açısından da katma değerlidir.

2. İletim yapılarındaki çeşitlenme: Sektörün hem pozitif hem de negatif etkilere maruz kaldığı çeşitlenme, radyo yayıncılığının FM/AM frekansa kısıtlı yapısından ve bu iletim teknolojisindeki sorunlardan kurtulmasına olanak sağlamaktadır. Aslında karasal yayıncılık hizmetleri dağıtım açısından en uygun fiyatlı ve gelir demografisine göre en geniş kitleye ulaşma potansiyeline sahip yayıncılık modelleridir. Ancak mobil cihazların yaygınlaşması ile genele yayılan yenilikler, değişen tüketici ortam ve alışkanlıkları, mobil cihaz üreticilerinin bu yayınları alabilecek donanımsal özellikleri desteklemek konusundaki isteksizlikleri, dijital iletim ortamlarının daha kaliteli ses hizmeti, dinleyicinin FM üzerinden yapılan geleneksel radyo yayınlarından uzaklaşmasına neden olmaktadır. Diğer yandan DAB gibi denenen ve karasal yayıncılığın çıkmazlarına bir çözüm olarak görülen teknolojilerde yaşanan sorunlar, geniş bant teknolojisinin yayılmasına paralel şekilde yayınların ulaştırılabilmesi için çok farklı seçeneklerin ortaya çıkması sektörün, FM/AM dışında yeni bir ana iletim teknolojisi konusunda uzlaşmasının önünde engel gibi görünmektedir.

3. Yakınsama ve Çoklu Platformlar: Bilgi iletim teknolojileri olarak adlandırılan bir yapının oluşmasına neden olan yakınsama, farklı teknolojilere sahip hizmetlerin bir potada erimesini mümkün kılacak bir ortam yaratmıștır. Radyo bugün hem dijital hem de analog platformlarda olmasının avantajının da farkındadır. $\mathrm{Bu}$ platformların getirdiği ek servisler, radyo istasyonlarının hizmetlerinde çeşitliliğin de önünü açmaktadır. Bu marka tanıtım ve pazarlama süreçlerinde sektörün elini güçlendiren içerik çeşitliliğine destek vermektedir. Öte yandan dijital teknoloji ile birlikte gelişen çok seçenekli ortam, dinleyicinin bu çeşitlilik içinde içeriği nasıl ve ne zaman tüketebileceği üzerine karar verme gücü, geleneksel radyo yayıncılığını zorlamaktadır. Sektörün büyük oyuncularının yön verdiği geleneksel yayın modelinin yanında irili ufaklı web istasyonları ve büyük müzik kütüphaneleri ile radyonun ana iş akışını oluşturan müziğe yeni bir tüketim penceresi açan müzik servisleri, gittikçe bireyselleşen tüketim süreçlerine ve parçalanan bir dinler kitleye işaret etmektedir. Son olarak mobil hizmetler ve mobil cihazlardaki artış her ne kadar radyo için yeni 
iletim yöntemler ve yayın kapsamını genişletmek gibi görünüyor olsa da radyo yayınlarının alımlanma yöntemleri de parçalanmıştır.

Bu başlıklar aslında birbirinin içine geçmiş durumdadır. Bu nedenle de endüstrinin sahip olduğu dinleyicilerinin değişen ihtiyaç ve isteklerini doğru analiz edebilmesi, bu ihtiyaç ve istekleri karşılayan diğer hizmetler ile rekabet edebilecek yaklaşımlar geliştirebilmesi esastır. Web üzerinde faaliyet gösteren çevrim içi radyo ve müzik servislerinin dinleyiciye sunduğu olanaklara karşı radyo istasyonlarının geleneksel iş modellerini terk etmeleri bir zaruret olarak ortaya çıkmaktadır. Radyo istasyonlarının yeni medya ortamları ile rekabet edebilirliği bu istasyonlardan çlkacak ve dinler kitle tarafından benimsenecek radyo kişilikleri (radyo şovmenleri, dj'ler vs) ile ilişkilenmektedir. Bu açıdan bakıldığında bir müzik hizmetinin sahip olamayacağı samimiyet radyonun var oluşundan bu yana getirdiği ve her zorunlu değișimde koruyabildiği en temel özelliğidir. Ĕger radyo ürettiği içerik ile konuşmanın ayırt ediciliğini destekler ise dijital dönüşümden başarılı bir şekilde çlkacaktır.

Öte yandan çevrim içi müzik çalma listeleri, bulut müzik servisleri gibi hizmetler ile dinleyicilere yeni deneyimler yaşatmak adına kişiselleştirilebilir ve/veya özelleştirilebilir hizmetler sunma çabaları son yıllarda artan bir şekilde karşımıza çıkmaktadır (Dünyada BBC IPLAYER, Türkiye'de Powerapp, Karnaval vs). Büyük radyo kuruluşlarının bünyelerindeki radyo istasyonlarını bir araya topladıkları ve çeşitli interaktif hizmetler sundukları portal radyoculuğu giderek önemini artırmaktadır (Özel, 2018). Bu tür teknolojik atılımların yanında, öncül saha araștırmalarında da görüldüğü üzere (Kuyucu, 2016, Bölükbaş ve Cengiz, 2017, Öztürk, 2018, Akyazı, 2016) radyo istasyonlarının internetin getirdiği web servisleri ve sosyal medya kullanım pratikleri, sektörün bir anlamda yeni medya düzeninde var olma noktasındaki inisiyatiflerini gösterir niteliktedir.

Son olarak bu çalışma, belirtildiği üzere, radyo sektöründeki değişimin kavramsal temellerine odaklanmıştır. Her ne kadar Avrupa ve Amerika'daki sektörler üzerinden elde edilen bulgular ve varsayımlar üzerine tartışılmış olsa da bu değişim, küresel anlamda kendisini hissettirmekte ve yerel coğrafyaların tamamı için de geçerli olduğu düşünülmektedir. Kuramsal kısıtları ile yapılmış bu çalışmanın saha araştırmaları ile çeşitlenebileceği ve farklı bulgulara da ulaşılabileceği göz ardı edilmemektedir.

\section{Kaynakça}

Akyazı, E. (2016). Yeni İletişim Ortamlarında Etkileșim Ve Mobil Radyolara Yönelik Bir Araştırma. Marmara İletişim Dergisi(22), 153-162.

Bölükbaş, K., \& Cengiz, G. (2017). Radyo Kanallarında Ve Radyo Programcılarında Twitter Kullanım Alışkanlıkları. Akademik Sosyal Araştırmalar Dergisi(62), 261-276.

Baker, A. J. (2009). Comparing the Regulatory Models of Net-Radio with Traditional Radio. International Journal of Emerging Technologies and Society, 1(7), 1-14.

Baker, A. J. (2011). College Student Net-Radio Audiences: A Transnational Perspective. The Radio Journal: International Studies in Broadcast and Audio Media, 2(8), 121-139.

Berry, R. (2006). Will the iPod Kill the Radio Star? Profiling Podcasting as Radio. Convergence: The International Journal of Research into New Media Technologies, 2(12), 143-162. doi:10.1177/1354856506066522

Berry, R. (2014). The future of radio is the internet, not on the internet. M. Oliveria, S. Grażyna, \& G. Starkey içinde, Radio: The Resilient Medium (s. 3-15). Sunderland, United Kingdom: University of Sunderland. 
Bonini, T. (2014). Doing radio in the age of Facebook. The Radio Journal- International Studies in Broadcast \& Audio Media, 1+2(12), 73-87. doi:10.1386/rajo.12.1-2.73_1

Bonini, T. (2015). The listener as producer: The rise of the networked listener. T. Bonini, \& B. Monclus (Dü) içinde, Radio Audiences and Participation in the age of network society (s. 1-36). London: UK:Routledge.

Carlin, T. (2006). Digital Audio. A. Grant, \& J. Meadows (Dü) içinde, Communication Technology Update 10th. Edition (s. 235-257). Oxford: Focal Press.

Cordeiro, P. (2012). Radio Becoming R@Dio: Convergence, Interactivity And Broadcasting Trends In Perspective. Participations Journal Of Audience\&Reception Studies, 2(9), 492-510.

Ferguson, D., \& Greer, C. (2011). Local Radio and Microblogging: How Radio Stations in the U.S are Using Twitter. Journal of Radio \& Audio Media, 1(18), 33-46. doi:10.1080/1 9376529.2011.558867

Fossi, M. A., Lax, S., O’Neill, B., Jauert, P., \&Shaw, H. (2008). The Future of Radio is Still DigitalBut Which One? Expert Perspectives and Future Scenarios for Radio Media in 2015. Journal of Radio\& Audio Media, 1(15), 4-25. doi:10.1080/19376520801971337

Gazi, A., \& Bonini, T. (2018). Haptically Mediated" Radio Listening and its Commodification: The Remediation of Radio through Digital Mobile Devices. Journal of Radio \& Audio Media, 1(25), 109-125.

Glantz, M. (2016). ) Internet Radio Adopts a Human Touch: A Study of 12 Streaming Music Services. Journal of Radio \& Audio Media, 1(32), 36-49. doi:10.1080/19376529.20 16.1155124

Hanson, K. (2011). Fourth Golden Age Is Almost. Youtube: Hanson, K. (2011), Fourth Golden Age Is Almost Here, (Video Dosyası), http://www.youtube.com/ watch?v=8ozaT5PHL_M adresinden alındı

Hendy, D. (2000). A Political Economy of Radio in the Digital Age,. Journal of Radio Studies, 1(7), 213-234. doi:10.1207/s15506843jrs0701_16

Holmes, D. (2009). New Media Theory. S. Littlejohn, \& K. Foss (Dü) içinde, Encyclopedia of Communication Theory (s. 684-687). California: SAGE Publications.

Jauert, P., Ala Fossi, M., Föllmer, G., Lax, S., \& Murphy, K. (2017). The Future of Radio Revisited: Expert Perspectives and Future Scenarios for Radio Media in 2025. Journal of Radio\&Audio Media, 1(24), 7-27. doi:10.1080/19376529.2017.1310574

Kuyucu, M. (2016). Instagram Radyonun Gizemini Öldürdü mü?Radyo Kanalları Ve Radyo Programcilarında Instagram Kullanımı. Ulakbilge, 4(7), 69-100.

Lax, S. (2017). Different Standards: Engineers' Expectations and Listener Adoption of Digital and FM Radio Broadcasting,. Journal of Radio\&Audio Media, 1(24), 28-44. do i:10.1080/19376529.2017.1297147

Lindgren, M., \& Gail, P. (2014). Radio reinvented: The enduring appeal of audio in the digital age. Australian Journalism Review, 2(36), 5-9.

Nyre, L., \& Ala Fossi, M. (2008). The Nex Generation Platform: Comparing Audience Registration and Participation in Digital Sound Media. Journal of Radio \& Audio Media, 1(15), 41-58. 
O’ Neill, B. (2009). DAB Eureka-147: a European vision for digital radio. New Media \& Society, 11(1-2), 261-278. doi:https://doi.org/10.1177/1461444808099578

Pitts, G. (2006). Radio Broadcasting. A. Grant, \& J. Meadows (Dü) içinde, Communication Technology Update 10th. Edition (s. 139-154). Oxford: Focal Press.

Pluskota, J. (2015). The Perfect Technology: Radio and Mobility. Journal of Radio \& Audio Media, 2(22), 325-336. doi:10.1080/19376529.2015.1083378

Priestman, C. (2013). Web Radio, Radio Production For Internet Streaming. New Yorke: Focal Press.

Punnett, I. (2016). ) Digital is the Future-And the Now: EmPosium on Digital Platform Listening Trends,. Journal of Radio \& Audio Media, 1(23), 4-19. doi:10.1080/19376 529.2016.1156394

Sinton, M. (2018). No Longer One-to-Many: How Web 2.0 Interactivity is Changing Public Service Radio's Relationship with its Audience. Journal of Radio \& Audio Media, 1(25), 62-76. doi:10.1080/19376529.2017.1370713

Stiernstedt, F. (2014). The Political Economy of the Radio Personality. Journal of Radio \& Audio Media, 2(21), 290-306. doi:10.1080/19376529.2014.950152

Özel, S. (2011). Yakınsama: Yeni Medyanın İtici Gücü. Erciyes Üniversitesi İletişim Fakültesi Akademik Dergisi, 2(2), s. 54-66.

Özel, S. (2014). Yeni Medya Çağında Radyoların Dönüşümü. Akdeniz Üniversitesi İletişim Fakültesi Dergisi(22), 168-189.

Özel, S. (2015). Çok Çesitli Medya Ortamlarında Gençlerin Geleneksel Radyo Dinleme Eğilimleri Üzerine Bir Araştırma. Selçuk Üniversitesi İletişim Fakültesi Akademik Dergisi, 4(8), 281-320.

Özel, S. (2018). Dijital Çağda Radyonun Dönüşümü: Platform Radyoculuğu. Communication In The Millennium , (s. 575-596). Eskişehir.

Öztürk, B. (2018). Gelenekselden Dijitale Radyo Yayıncılığı ve Aktif Dinleyici. Uluslararası Dijital Çağda İletişim Sempozyumu (s. 80-87). Mersin: İletişim Araştırmaları Derneği (ILAD). 


\title{
Digitalization in Radio: Understanding Tomorrow for the Sector
}

\author{
Sedat Özel (Assoc. Prof. Dr.)
}

\section{Extended Abstract}

While digital technologies change the style of cultural production and consumption today, the radio as a cultural industry, experience this change powerfully. Starting with the change of convergence in knowledge and communication technologies, the alteration becomes visible initially with the production in radio content right after the transmission methods but mostly in the process of production. Different service and contents offering to the audience as in the other traditional communication tools led to loss of audience particularly the cloud services. Researches underline that the loss is not that intense, however, it indicates a danger to the radio with the effect of generation $\mathrm{Y}$ who are more willing to use the new communication media and tools. The future existence of the radio is depended on the stronger use of technology by protecting its distinctives, fundamental properties and involvement of the features such as interaction, privatization, asynchronous communication which are available in the new media.

\section{Digital Technologies and Changing Conditions in Broadcasting}

Digitalization and the internet technologies are changing the media market, affecting the radio fundamentally. According to those who claim this view, there has been a great increase in leisure time spent on the entertainment. In parallel with this, new types of entertainment emerged. In this new world, which cannot be limited to just radio, TV, magazines or newspapers; all contents, including video games, although having their own media in the past, is now presented to the consumer on web basis (Cordeiro, 2012). Hendy (2000), claims that digitalization has two main aspects in radio and defines these as "digitalization of production" and "digitalization of distribution". The digitalization of distribution includes innovations in the transmission of sound both in traditional air broadcasting and in the Internet.

Digitalization is discerned as the finale of deregulation. In the same vein, advocates of digitalization states that there will be a large expansion in the number of ways to make an application realizing the definition of niche radio where "a reality" creates space for meaningful public choice and greater local participation, and enables the audience to become more active as a consumer and a citizen (Hendy, 2000).However, it has to be noted that the business model dominating the radio is based on marketing audience's attention through advertisements, within this context, information and entertainment content is marketed. In this case, radio broadcasting is part of the culture industry.

Binary coding is also the main feature of the digitalization of distribution. DAB's principle of operating grounded on binary coding provides a way to effectively compressing the signal data in the broadcast spectrum, but also it allows the transmission of several broadcast or program services on a single frequency. DAB, which stands out with its ability to provide superior sound quality strikingly, increases the number of radio services that can fit into airwaves. Binary data can be transmitted across computer networks as it can be transmitted through the air. This constitutes the basis for radio technology over the Internet. In fact, the "beginning cost" for this type of web publishing is relatively low. A single computer that functions as a server and relatively inexpensive software is needed. 
It is a fact that many radio stations do not bother to make traditional broadcasts and broadcasting only on the internet with such an investment (Hendy, 2000).

In addition, platforms that provide music services on the Internet and radio broadcasting are used interchangeably. Even in industry literature, digital platforms and digital radio are frequently used that way (Punnett, 2016, s. 5). Yet, Black questions whether the delivery of an audio signal over the internet can be called radio in the first place. If radios that broadcast over the WEB are a different medium, why do they use the term "radio"? Black offers that this medium, which stands out with its interactive services, cannot only be called radio (Baker, 2009: 8 from 2001). Tacchi, on the other hand, accepts that Web radios are not like conventional radio, but refers to the ability of the internet to act as a radio with the expression of radiobility (Baker, 2009: 8 from 2000: 289-292).

\section{Present and Future of Radio}

In the early 2000s, when technological change was strongly felt in the broadcasting field, there was a pessimistic approach for theradio. The effects of technologies such as CD and MP3 to strengthen individual consumption bestowed strong evidence that the organizations that catch up the radio industry would be in a deadlock if they cannot respond correctly to such developments. In the following years, growing interest in music services that challenged the impact of radio on music consumption has caused more concerns about the devastating effects of new technologies on the industry.

In fact, since the radio's first commercial broadcast in 1920, the radio has faced numerous changes and challenges. From format changes to the impact of creative advertising messages, the radio has successfully accomplished the change that is part of its growth as a broadcast medium. Besides, radio has given a successful test against many market threats such as phonograph, cassette, CD, which were beyond the change, specific to the growth and development of an environment. However, perhaps one of the most important threats to radio today is the unresolved threat put forth by the Internet. As a ramification of the Internet and mobile networks, radio's greatest asset - portability - has also become its biggest obligation. Radio is a traditional and reliable technology, but the way broadcasts are delivered and the lack of interaction threatens its future (Pluskota, 2015).

Changes in media consumption have pushed us to think of a new type of listener who is both an audience and producer. This type of listener is actively producing content in the social context of web 2.0 while being a listener at the same time. From this point of view, the radio is no longer only has listeners, it actually exists online and has a new way of listening; in this respect, it has an audience to be called "e-listeners". "E-listener" is more than just a radio listener. It is a cross-media and multi-platform media consumer that interacts with the media (and especially with the radio) in any way possible, interacting and producing content (Cordeiro, 2012).

In this context, the main question for the survival of the sector is not how many stations there are, but the content and service variety of these stations. In a multi-choice broadcasting environment, where cloud-based music services are the main competitor, DJs strive to direct the audience towards more content on the station's website providing a social network control. Now, the important thing for the radio is not only to keep the audience on the channel but also to move between different media platforms under the brand's umbrella (Stiernstedt, 2014). 
Technology, which supports internet-based media listening experiences, represents the developments that terrestrial radio stations should embrace. The terrestrial broadcasting radio industry should focus on developing its broadcast technology architecture in an extent to compete with Internet-based media listening experiences. The possible solution is that the radio industry adopts an on-demand mentality, as the radio industry is trying to revive and transform itself. The substantial challenge is that if the radio decides to adopt such a transformation, the industry would have to reassess the cost structure and costs depending on its ability structure (Pluskota, 2015).

Keywords: Radio Broadcasting, Digitalization, Convergence ,Internet Radio. 